\title{
Species monitoring through space and time - combining microfluidic SNP genotyping and environmental niche modelling on herbarium specimens of the rare Northern dragonhead, Dracocephalum ruyschiana (Lamiaceae)
}

\author{
Malene Nygaard ${ }^{1}$, Alexander Kopatz ${ }^{2}$, James Speed ${ }^{1}$, Mike Martin $^{1}$, Tommy Prest $\varnothing^{1}$, \\ Oddmund Kleven ${ }^{2}$, and Mika Bendiksby ${ }^{3}$ \\ ${ }^{1}$ Norwegian University of Science and Technology \\ ${ }^{2}$ Norwegian Institute for Nature Research \\ ${ }^{3}$ University of Oslo
}

December 13, 2021

\begin{abstract}
Aim: We have studied population genetic change through time in the Northern dragonhead, Dracocephalum ruyschiana (Lamiaceae); a plant species that has experienced a drastic population decline and habitat loss in Europe. We aimed at adding a historic level to the monitoring of dragonhead by testing a microfluidic SNP array approach on herbarium specimens up to 200 years old and comparing the genomic results with that of modern populations in Norway. We also aimed to gain a more holistic species knowledge to guide monitoring efforts by combining herbarium genomics with ecological niche modelling (ENM). Location: Europe (mainly Norway) Methods: We have applied a microfluidic array consisting of 96 SNP markers on 130 herbarium specimens collected from 1820 to 2008. Obtained genotype data were compared with SNP data from modern samples using various population genetic analyses. We used sample metadata and observational records to model the species' environmental niche. Results: The SNP array successfully genotyped all included herbarium specimens but was less capable of capturing diversity outside of Norway, which was genetically highly divergent from the Norwegian dragonheads. The historic-modern comparison revealed similar genetic structure in space and limited change through time in Norway. The ENM suggests that dragonhead has not fully achieved its potential distribution in Norway, which is anchored in warmer and drier regions, including areas where it does not occur today. Main conclusions: With the appropriate design procedures, the SNP array technology is promising for genotyping old herbarium specimens; an invaluable source of information from the past. We found no signs of the severe reduction in population size in our temporal genomic data of Norwegian dragonhead. Regardless, the regional populations in Norway are genetically divergent, both from each other and more so from populations outside of Norway, rendering continued protection of all existing populations of the species relevant.
\end{abstract}

\section{Hosted file}

Nygaard_et_al_Main-document_for-EE.docx available at https://authorea.com/users/450952/ articles/549214-species-monitoring-through-space-and-time-combining-microfluidicsnp-genotyping-and-environmental-niche-modelling-on-herbarium-specimens-of-the-rarenorthern-dragonhead-dracocephalum-ruyschiana-lamiaceae

\section{Hosted file}

Fig1-8.pdf available at https ://authorea.com/users/450952/articles/549214-species-monitoringthrough-space-and-time-combining-microfluidic-snp-genotyping-and-environmental- 
niche-modelling-on-herbarium-specimens-of-the-rare-northern-dragonhead-dracocephalumruyschiana-lamiaceae 